\title{
Unfold the Veil Covering News - A Case Study of English Language and Ideology in both American and Chinese Press
}

\author{
Li Gao ${ }^{1} \&$ Qi-Dongmeng You ${ }^{2}$ \\ ${ }^{1}$ School of Foreign Studies, Henan Polytechnic University, China \\ ${ }^{2}$ Department of Foreign Languages, Hainan Normal University, China \\ Correspondence: Li Gao, Schoolf of Foreign Studies, Henan Polytechnic University, Jiaozuo, Henan, China. Tel: \\ 86-391-398-9600. E-mail: gaolihpu@gmail.com
}

Received: July 10, 2013 Accepted: July 29, 2013 Online Published: September 4, 2013

doi:10.5539/elt.v6n10p179 URL: http://dx.doi.org/10.5539/elt.v6n10p179

\begin{abstract}
By taking Systemic Functional Grammar (SFG) as research approach, this study analyzes and discusses two news reports related to the event that a Uyghur man was sentenced to death by the Intermediate People's Court in Xinjiang, a western province of China. Both news reports on that event are taken respectively from two newspapers published in English language but with clearly opposed ideology, CNN and China Daily. We have found that, however, these two news reports are quite different and even completely opposite in making use of three saliently patterned linguistic features, that is, transitivity, naming of news actor and quotation patterns. We argue that the different even opposite selection in the three aspects in the two news reports are not arbitrary, but rather are ideologically motivated. Finally, we suggest that teachers are supposed to teach and help students read news reports with critical eyes.
\end{abstract}

Keywords: SFG, news report, English language, ideology

\section{Introduction}

In the era of information, news reports play an important role in providing us with rich resources about what's happening around the world. However, it is agreed that news reports can never be really objective and neutral but serve the ideologies held by the press (e.g. Kuo \& Nakamura, 2005). And their biased stances might influence readers' interpretation of the reality and hinder them from knowing the "truth". Sometimes, deliberate choices would be made to "manage public's opinion" (Lukin, Butt \& Matthiessen, 2004, p.61). Therefore, we as readers are suggested to be critical when processing all those information rather than get used to it (e.g. Lukin, 2003). And as teachers, we are reminded of the responsibility of helping our students to "manage and evaluate the virtual bombardment of reports from news media" (Lukin, 2003, p. 18).

But the question is how to be critical. In this essay, by comparing two news reports, we will explore how the choices of language would reflect the underlying stances and construct "different 'takes' on reality" (Lukin, 2003, p. 20), from the dimensions of Field and Tenor, in the hope of informing the public of some specific ways to be critical and the teachers of some tangible tools to help students become critical in news reading.

To be more specific, we will take the approach of systemic functional grammar (SFG) to analyze three language features-transitivity, naming and quotation patterns. Firstly, SFG is considered as the powerful tool to explore the ideological effects of different linguistic choices in constructing different "reality" (e.g. Lukin, 2003; Lukin, et al., 2004). Secondly, these three features are the typical ones to be analyzed for revealing ideological impact of news and have been proved to be quite effective (e.g. Lukin, 2003; Kuo \& Nakamura, 2005). Thirdly, they are found saliently patterned in the news selected.

The two pieces of news we have chosen are from the same day, March 28, 2012, and reported on the same event that a Uyghur man was sentenced to death by the Intermediate People's Court in Xinjiang, a western province of China. One is from China Daily (News A, see Appendix A), a state-owned press by China, and the other from CNN, (News B, see Appendix A), a famous American press. Since issues related with China have gradually become the center of discussion, our study is supposed to be of great interest.

In the following parts, our analysis will focus on the dominant aspects within each of the three language features. 


\section{Analysis of Linguistic Features}

\subsection{Transitivity}

The notion of transitivity is closely related with three elements - processes, participants, and circumstances (Delin, 2000). Analyzing transitivity means analyzing "different choices in type (and number) of processes, participants, and circumstances" (Coffin, Donohue \& North, 2009, p. 292), or more simply, "analyzing the components of language that function to represent "who does what, to whom, where, when, and how" (Coffin, et al., 2009, p. 288). Those different choices are subject to the perspectives of the language users (Coffin, et al., 2009, p. 309) and would "create different 'angle on the world"" (Coffin, et al., 2009, p. 292-293). Therefore, examining transitivity can help us to understand how the underlying stances are reflected and how the different angles are created through language choices.

In previous studies, it seems that transitivity analysis for revealing different stances can be more effective in the comparison between sentences of the "same" content (e.g. Lukin, 2003). Accordingly, we found seven pairs across News A and B sharing "similar" content and analyzed them in terms of process, participant and circumstance (see Appendix B). A significant difference was found in their choices of process as follows.

Table 1. The choice of material process and verbal process in the two news reports

\begin{tabular}{lcc}
\hline Resources & Material process & Verbal process \\
\hline China Daily & 16 times (all a. except 6.a.) & 1 times (6.a.) \\
CNN & 5 times (1.b., 4.b., 6.b., 7.b.) & 4 times (2.b., 3.b., 4.b., 5.b.) \\
\hline
\end{tabular}

As shown in Table 1, the dominant process in News A is Material process while in News B, both Material and Verbal processes seem equally important. However, within the verbiage in News B, all the processes are material one, up to seven times. What makes the difference even more significant is the language choice of participants and those processes.

Table 2. The choice of participant and process in the two news reports

\begin{tabular}{|c|c|c|c|}
\hline \multirow{8}{*}{$\begin{array}{l}\text { China } \\
\text { Daily }\end{array}$} & \multicolumn{2}{|l|}{ Participant (frequency) } & Process \\
\hline & \multirow[b]{2}{*}{ “terrorist" and his group (8) } & Actor (4) & "gets [death sentence]","went", "attacked", "died" \\
\hline & & Goal (4) & $\begin{array}{l}\text { "was sentenced to death", "was found guilty", } \\
\text { "was captured", "was wounded" }\end{array}$ \\
\hline & \multirow[t]{2}{*}{ “police” group (4) } & Actor (2) & $\begin{array}{l}\text { "rushed <to the scene>", "shot...[terrorists] } \\
<\text { dead }>\text { " }\end{array}$ \\
\hline & & Goal (2) & "was killed", "were injured" \\
\hline & \multirow{2}{*}{ "people" (3) } & Actor (2) & "died", \\
\hline & & Goal (1) & "were injured" \\
\hline & "terrorist attacks" (1) & Actor (1) & "occurred" \\
\hline \multirow{4}{*}{ CNN } & \multicolumn{2}{|l|}{ Participant (frequency) } & Process \\
\hline & \multirow[t]{2}{*}{ "China" and her group } & Actor (4) & "sentence...to death", "detained", "shot...dead", \\
\hline & & Sayer (4) & "reported" (2), "said" (2) \\
\hline & Xinjiang (1) & Goal (1) & "was rocked" \\
\hline \multirow{4}{*}{$\begin{array}{l}\text { The Said } \\
\text { in CNN }\end{array}$} & \multicolumn{2}{|l|}{ Participant (frequency) } & Process \\
\hline & “a local court" (3) & Actor (3) & $\begin{array}{l}\text { "has sentenced...to death", "convicted", } \\
\text { "sentenced...to death" }\end{array}$ \\
\hline & "Uygur man" and his group (2) & Actor (2) & "killed", "wounded" \\
\hline & "policeman" group (2) & Goal (2) & "were wounded", "was killed" \\
\hline
\end{tabular}

From Table 2, it is clealy seen that two reports mainly differ in the way of reporting who did what to whom.

In News A, "terrorist" is a focus of information describing what he and his group members did and what damage they have caused. Those material processes do not only directly relate "Mamut" and his group members with the actions of "killing" and "attacking" as the actors, but also present the "account dynamic" (Coffin, et al., 2009, p. 295 ) and vivid as if they were happening before the audience. The cruelty and the tragic consequence of their actions become more direct, real and shocking and thus it is more likely to get readers' hatred towards the 
"terrorist" and their agreement with the "court's" judgment. Even though the "terrorist" group has been the goal for four times, it doesn't affect their negative image. For example, in 3.a., "Abdukerim Mamut was found guilty of running a terrorist organization, leading terrorist attacks and murder", the man is not only defined as "guilty", but also again presented as the initiator of those crimes. All the impression it leaves is that the man has done terrible things and he deserves the punishment. This is further emphasized by moving away or making implicit the sentence giver "the court" by passive voice in 2.a. and 3.a. and by middle voice in 1.a.. Particularly in 1.a., by adopting the middle voice which is considered as a "powerful way of effacing agency" (Lukin, et al., 2004, p. 63 ), and placing the "terrorist" as the agent followed by the verb "gets", it probably suggests that the man is the real reason of getting himself sentenced rather than anyone else. This perspective is typically crucial because as the title of the news report, it will bias readers' understanding and interpretation of the whole news (Kuo \& Nakamura, 2005). Meanwhile, the police "rushed to the scene" and saved other people's life, and "were wounded" in their heroic and righteous actions. What's more, labeling the man as "terrorist" further suggest he is the one who must be guilty and should be universally criticized. All the language choices reflect the idea that the man is extremely guilty and should deserve a punishment as severe as death sentence and what the Chinese government has done is fair and right.

However, in News B, things are totally different. The man is always placed at the position of Goal in the actions by Chinese government. As Coffin et al. (2009) points out, it is the agent that typically brings about changes, i.e. it is "China" that makes the change, to "the man". To be specifically, it is "China" that initiates the action of sending the "Uyghur man" to jail and thus should be responsible for his miserable result. Therefore, "China" is made as the external reason of the man's punishment and the "Uyghur man" himself seemingly has little responsibility and may just be a passive sufferer of the action by "China". While in the verbal process, the man is always placed in the Verbiage. Both positions seem to suggest that he is the sufferer of Chinese governmental power of administration and speech.

Besides directly reporting what Chinese authorities did to the man, News B moves the verbal process at the end of the whole sentence when quoting directly or indirectly what "the court" has done to the man. Take 2.b. as an example.

"A local court in the far western Chinese province of Xinjiang has sentenced to death a Uyghur man who it says led an attack in a busy street last month that left 15 people dead, Chinese state media reported".

The verbal process is clearly separated from the Verbiage with comma, functioning more like a circumstance as the phrase "according to the Chinese state media" does. Since "circumstances... are more peripheral" compared with process and participants (Coffin, et al., 2009, p. 289), such positioning downplays the role of the verbal process and simultaneously greatly foregrounds what is said. And in the Verbiage, the man becomes the affected by the action initiated by the "court" again, continuing to emphasize the implication that it is China that brings about the suffering to the man. Although there is an embedded relative clause led by "who" to describe the crime done by the "Uyghur man", this grammatical structure has already "grammatically marginalized" its own content (Lukin, et al., 2004, p. 71). What's more, the naming of the court matters. Here it is "a local court in the far western Chinese province"- a place seems to be poor and uncivilized. Such association would mitigate the authority and expertise of the court and thus the fairness of its judgment. To the contrast, in News A, it is "the Intermediate People's Court". This official name is more likely to encourage readers to admit the authority, expertise and thus judgment of the institution.

Oppositely, when what the "Uygur man" has done is reported, the verbal process will be placed at the very beginning of the whole sentence. Take 4.b. for example.

"It said Mamut and other members of the group killed 15 people and wounded 14 others "with axes and knives" in Yecheng County on February 28."

Having its Sayer and the verbal process at the very beginning, the sentence clearly indicates a relation of subordination, an embedding structure. As suggested by Thornborrow (1994), the structural embedding of clauses whose agent is "Mamut and other members of the group" into main clause whose agent is "It (Global Times)", would mitigate the actions of "killing and hurting" and agency of "Mamut" as the killer and attacker, and suggest more initiation of "It" to those actions. In another word, it potentially implies that Mamut's killing may not be a solid fact but is heard from some subjective saying. Moreover, what "Mamut" has done is presented in the Verbiage, as if it is a static picture or abstract things, which will have less impact on the readers than dynamic actions (Lukin, et al., 2004). In all, the language choices in News B would create such an impression that this man is innocent and suffer from the cruel and unfair governing of Chinese government or, to be more specific, of "Han population". It is more likely to elicit readers sympathy for the "Ugyhur man" while 
aversion against Chinese government. This perspective has been established as early as from the title as News A does and is also facilitated by its less empathetic reporting about Chinese policeman, e.g. "The Chinese authorities said four policemen were wounded and one local securing officer was killed in the clash" (5.b.). Separating the victim talked about to be the sayer of the event would place the sayer in a less sympathetic position (Delin, 2000). Therefore, placing "Chinese authorities" as the sayer of the tragedy happening to the Chinese police and officer would be less likely to evoke readers' sympathy for those "police and officer" who are part of the "Chinese authorities".

According to the analysis above, we can see that through different language choices, two news reports create different takes on reality - the "terrorist" murdered people and deserves the death sentence (by China Daily) or the "Uyghur man" got prisoned by Chinese government and he probably has done nothing but just suffers from the suppression by Chinese government (by CNN). Their difference in representing the "reality" in fact reflect their opposed perspectives to the event—one is for the Chinese government's judgment of death sentence while the other is totally against. And the CNN news even implies the disagreement of the Chinese Government as a whole.

\subsection{Naming of the News Actor}

In this section, we will consider how these two pieces of news construct their ideologies through different lexical choice of naming actors. Naming of news actors is one of the various forms taken by referencing forms in news event. Different choice in referencing to news actors can not only characterize and specify the referent's social role or position, but also can reveal the evaluation and attitudes of the journalist toward the actors (Fowler, 1991, cited in Kuo \& Nakamura, 2005). Similarly, naming in vocabularies with different connotations can also show the ideological slant of a news report. (Delin, 2000)

These two pieces of news in our data show distinct difference in naming the main actor, a Uygur man, whose name is Abdukerim Mamut. Expressions used in these two news reports to refer to the main news actor are shown in the following table. The numbers in parenthesis represent the number of times each descriptive label is used.

Table 3. Expressions used in the two news reports to refer to the main news actor

\begin{tabular}{lc}
\hline China Daily & terrorist (2), ringleader (2) \\
\hline CNN & Uyghur man (2) \\
\hline
\end{tabular}

The different lexical choices of the descriptive labels shown in Table 3 construct sharp contrast with regard to the impression of readers on this news actor.

With salient negative effect, the word terrorist in News A, positions Mamut as someone whose existence threatens the safety of people and even who greatly probably brings death to people, especially to those innocent and weak ones. Compared with terrorist, the word ringleader entails even more strongly negative connotation in that Mamut not only by himself behaves dangerously towards public order and safety but also instigates others to follow him and form more and bigger threats to people. While, the choice of the phrase Uyghur man in News B, positions Mamut as an average civilian, who lives in Xinjiang and belongs to the Uyghur minority group, as common as anyone among thousands of Uyghur people there.

It has been discussed that both negative and positive words entails affective meaning in that they indicate something of the attitudes and evaluation of the journalist toward the person referred to (Delin, 2000; White, 2004). The different selection of words to name Mamut signals the different perspectives of the two newspapers about this event, which also reflects their political stance behind. By terrorist, News A sees Mamut as an enemy; while, News B just considers him a common civilian by the phrase "Uyghur man".

In News A, given the background knowledge of terrorists most readers harbor, such as the disastrous consequence resulted from the horrible terrorist attack, readers will judge that Mamut, a terrorist and a ringleader of a terrorist group, is supposed to be sentenced to death or deserves the death sentence. It is hard for readers to generate sympathy or pity for a terrorist. In contrast, in news B, it seems normal for a court to sentence Mamut to death for what he did, but at the same time some affection or even sympathy may be activated on the part of readers for the selection of the phrase Uyghur man instead of terrorist. The reason behind this lies in the following two aspects. On the one hand, average people are in common sense considered as the weak part in front of government; on the other hand, minorities is usually taken as inferior to majorities. People's attitudes 
toward an average minority man and a terrorist will definitely differ in a great sense. Thus, readers of news A and $\mathrm{B}$ are positioned in different stance in terms of their attitude towards Mamut.

Another point which can reinforce the effect of the different lexical choice of naming Mamut is that both of them appear in the news headline. Headline usually contains the crucial information of the whole news and thus such a summary necessarily implies a perspective on a news event, which "may bias the understanding process and influence the interpretation made by the readers" (Van Dijk, 1991, cited in Kuo \& Nakamura, 2005, p. 400). Cognitively headline is strategically used by readers to construct the overall meaning of the news event (Kuo \& Nakamura, 2005). With the word terrorist in the headline, News A makes reader takes it for granted that Mamut is an ethically bad man. Thus, the process is natural for readers to accept that Mamut deserves death and Chinese government does justice to people. While, with the descriptive phrase Uyghur man in News B, readers will not generate as much negative emotion as in News A.

According to the above analysis, News A and B show overtly different attitudes towards this news event by different lexical choices in naming Mamut. Apart from that, different attitudes among readers are strategically aroused in terms of this event.

\subsection{Quotation Patterns}

The next aspect we will look at is the quotation patterns in these two news reports. Quotation is a pervasive feature in news text. While, quotation mode traditionally includes two types, i.e. direct and indirect, mixtures of two types, that is, indirect speech incorporating direct speech or direct speech incorporating indirect speech, are found frequently used in news text too (Kuo, 2003). Literature (Avery \& Kim, 2008; Gibson \& Zillman, 1993; Kuo, 2003; Kuo \& Nakamura, 2005) has discerned some specific characteristic and general functions of quotation in news text. It is generally believed that apart from vividness, precision or dramatic effectiveness, quotation is never a neutral measure but a mediated strategy embedded with ideological bias.

In both News A and News B, it is easy to find out that all the three types of quotation mode are adopted but with some differences as we can see in the following tables. The first column on the left in each table explains the quotation sources.

Table 4. The indirect quotation, direct quotation and mixed type in News A

\begin{tabular}{lccc}
\hline Indirect quotation & Direct quotation & Mixed type & \\
\hline Chinese authority & 6 & 1 & 0 \\
Uyghur authority & 0 & 0 & 0 \\
\hline
\end{tabular}

Table 5. The indirect quotation, direct quotation and mixed type in News B

\begin{tabular}{lccc}
\hline Indirect quotation & Direct quotation & Mixed type & \\
\hline Chinese authority & 3 & 0 & 2 \\
Uyghur authority & 3 & 1 & 1 \\
\hline
\end{tabular}

As shown in Table 4 and Table 5, in total number, there are 7 quotations in A and 10 in B with the same number 6 of indirect quotation in both, which exhibits the similarity between them.

After taking another look it will be discovered that in News A, there is no quotation from Uyghur authority and it is typically one-sided quotation news report; while, in News B, quotations are from both Chinese authority and Uyghur authority. Second, no mixed type is used in News A but there are 3 mixed type in News B with 2 in quotation from Chinese authority and 1 from Uyghur authority.

Being frequently woven into the fabric of news report, quotation can not only make the news livelier but give it a semblance of authenticity and factuality. Therefore, it is common journalistic tool in news reports. While, the selection of quotation source, however, involves journalists' evaluation and attitude, as Kuo (2003) has discovered that generally the journalists tend to quote those who voice the position of the newspaper. In News A, quotations seemingly from three different sources, i.e. Chinese official website, Chinese authoritative party chief and Chinese official local court, are all sub-branches of Chinese government or pro-Chinese communist party. There is a salient one-sided quotation pattern in News A, which entails explicit journalistic attitude and evaluation of this news event, that is, they are pro-Chinese communist government.

In contrast with News A, News B appears more objective with quotations from two politically opposite sides. 
The 10 quotations are evenly attributed to those two sides. Furthermore, by comparing the quotations from those two sides, we can see both are quoted indirectly for 3 times but one direct quotation and one mixture type from Uyghur authority and two mixture types from Chinese authority. With the notion that indirect quotation usually appears to indicate the agreement of what is said on the part of the journalist, it looks like the journalists of News B take what both sides said as authentic. We may discover, however, the journalistic stance is strategically and implicitly revealed through a close analysis.

First, Compared with indirect quotation, direct quotation is used to dissociate journalists with what is said or to distance journalists from the quoted words, but as Kuo (2003) shows direct quotation inevitably filters the quoted speaker's message by the selection of words and the choice of arranging materials. Through the quotation of Kadeer, the president of the Uyghur congress instead of Chinese party chief, Zhang Chunxian, the journalistic stance of News B is revealed to a certain degree. On the part of readers, indirect quotation, especially the one embedded with strong attitudinal vocabulary like this Kadeer quotation, "can influence news media consumer's perception of reality and judgment of issues" (Gibson \& Zillman, 1993).

Second, the mixture types used in News B reflect the different attitude of the journalists toward China and Uyghur. As shown below, (1) is the mixture type of quotation from Chinese authority and (2) is from Uyghur authority.

(1) The court in the Xinjiang Uyghur Autonomous Region convicted Mamut of "organizing and heading a terrorist group, and intentional killing" and sentenced him to death on Monday, the Global Times, an English-language newspaper run by the Communist Party, reported.

(2) It said Mamut and other members of the group killed 15 people and wounded 14 others "with axes and knives" in Yecheng county on February, 28.

(3) The quick conviction and sentencing of Mamut in connection with the violence "casts serious doubts on the legitimacy of the trial, and we do not believe that it met international legal standards," Rebiya, Kadeer, the president of the congress, said in a statement published Tuesday on the organization's website.

To begin with rephrasing the Global Times' report about the court verdict by indirect speech, the journalists take a sudden replacement of paraphrase with direct quotation when it comes to the description of Mamut's crime. Based on that general role of direct speech in absolving journalists from endorsement of the linguistic form in the news source, this sudden change from indirect to direct and the sharp contrast construed by it reinforce the fact that Mamut's crime described here has nothing to do with the journalists and that is only what Chinese authority said. It works similarly in (2). With the same mixture type of quotation, the case, however, is different but very interesting in (3). First of all, the journalists' dissociation in (3) is achieved similarly as in (1) and (2). But simultaneously an appreciation word "quick" is strategically inserted into the rephrasing part. Whatever related with court should be given seriousness and justice, so the conviction is used to be slow, say nothing about sentencing people to death. The phrase "quick conviction" implies that Mamut may not receive fair trial and Chinese government did not take it seriously, which entails the journalists' negative judgment of Chinese government and also can trigger negative attitude toward China on the part of readers.

Third, the arrangement of the quotations from both sides also speaks. Basically, the quotations from the two sides are arranged in accordance with the topic. It is noticeable that the quotations from Chinese authority are always followed by the quotation from Uyghur authority as the counterpart with opposite statements or unfavorable remarks. By putting what Chinese authority said before Uyghur authority, the situation is constructed under which the quotation from Chinese authority sets a target and every target is hit by Uyghur authority and then stops with no further chance for Chinese authority to hit back. Thus, the journalists of news B impresses readers that Uyghur authority is more reasonable and deserves more support in terms of this news event.

The close analysis of quotation patterns here seems to reinforce the fact that journalistic attitude and evaluation is involved in news text. It can take different forms, such as different quotation mode, delicate arrangement of quotations in a piece of news.

\section{Conclusion}

This essay, by adopting SFG, takes a close look at two pieces of news reports on the same event from China Daily and CNN, which hold different stance politically and ideologically. Through the analysis of three saliently patterned linguistic features in them, that is, transitivity, naming of news actor and quotation patterns, we find that these two news reports are quite different and even completely opposite in making use of the three linguistic features. These differences construct such a notion that they embed their own journalistic attitude and evaluation 
of this news event in the news text and furthermore successfully activate readers to share the same perception of reality and judgment of this issue. China daily serves for Chinese government under the control of Chinese communist party but $\mathrm{CNN}$ is against it. Our analysis of these two news reports just provides testimony to this.

With the notion of newspaper serving different organizations or governments, readers are supposed to think critically when processing the information given by them. As college teachers, we are suggested to inform students of the fact that writers have to take a perspective whenever and whatever using language to express, and it is the same in news report. Teachers are supposed to take the responsibility of helping students become a critical reader.

\section{References}

Avery, E., \& Kim, S. (2008). Comprising or compromising credibility? Use of spokesperson quotations in news releases issued by major health agencies. Public Relations Journal, 2(4), 1-18.

Coffin, C., Donohue, J., \& North, S. (2009). Exploring English grammar: From formal to functional. New York: Routledge.

Delin, J. (2000). The language of everyday life. London: SAGE.

Gibson, R., \& Zillman, D. (1993). The Impact of quotation in news reports on issue perception. Journalism Quarterly, 70(4), 793-800. http://dx.doi.org/10.1177/107769909307000405

Kuo, S. H. (2007). Language as ideology: Analyzing quotations in Taiwanese news discourse. Journal of Asian Pacific Communication, 17(2), 281-301.

Kuo, S. H., \& Nakamura, M. (2005). Translation or transforming? A case study of language and ideology in the Taiwanese press. Discourse Society, 16(3), 393-417.

Lukin, A. (2003). Lessons in grammar: How ideology shapes the reporting of war. Education Links, 66/67, $18-20$.

Lukin, A., Butt, D., \& Matthiessen, C. (2004). Reporting war: Grammar as 'covert operation'. Pacific Journalism Review, 10(1), 58-74.

Thornborrow, J. (1994). The woman, the man and the filofax: Gender positions in advertising. In S. Mills (Ed.), Gendering the reader (pp. 128-132). New York: Harvester Wheatsheaf.

White, P. (2004). Subjectivity, evaluation and point of view in media discourse. In C. Coffin, A. Hewings, \& K. O’Hallosan (Eds.), Applying English grammar (pp. 229-246). London: Arnold.

\section{Appendices}

Appendix A - News

News A - China Daily

Xinjiang terrorist gets death sentence

Updated: 2012-03-28 07:42

The ringleader of a terrorist group was sentenced to death on Monday by the Intermediate People's Court of Kashgar prefecture in the Xinjiang Uygur autonomous region.

Abdukerim Mamut was found guilty of running a terrorist organization, leading terrorist attacks and murder, according to Tianshannet, a news website run by the regional government's information office.

Under Chinese law, he has the right to appeal the conviction and sentence.

According to trial information posted on the website, Mamut preached religious extremism to a circle of followers and founded a nine-member terrorist organization with himself as ringleader.

They selected targets and planned attacks, including checking the locations.

On the morning of Feb 28, according to the website, Mamut called the members together at his house, handed out knives and axes and instructed the group in the details of an attack to be carried out that day.

At 6 pm, they went to a crowded pedestrian street - Xingfu Road in Yecheng county near Kashgar in the southern Xinjiang - and attacked people with the knives and axes. Thirteen people died and 16 were injured. Two of those people later died.

Police rushed to the scene and Mamut was captured. They shot seven terrorists dead and one was wounded and later died. 
One member from the public order joint defense force was killed and four police officers were injured.

Prosecutors presented evidence proving Mamut's guilt, including his confession, the website said.

The defendant's relatives and some of the victims and their families were among those attending the trial.

Zhang Chunxian, the Party chief of the region, recently said the attack was the result of agitation by overseas separatists, extremists and terrorists.

"The social situation in nearby countries and international anti-terrorism activities may have directly or indirectly prompted such incidents," Zhang said on March 7 on the sidelines of the annual session of the National People's Congress.

No mercy will be shown to those guilty of violent terrorist attacks in Xinjiang, Zhang said, and the government will not allow terrorists to wave knives at women, children and innocent people.

Yecheng county, in Kashgar prefecture, is about $1,500 \mathrm{~km}$ from the region's capital Urumqi. The county neighbors Kashmir region and is populated mostly by Uygur people.

Two similar terrorist attacks occurred in the prefecture in July, killing 14 people and leaving 42 wounded.

http://www.chinadaily.com.cn/cndy/2012-03/28/content_14927483.htm

News B - CNN

China sentences Uyghur man to death after violence

March 28, 2012 - Updated 0712 GMT (1512 HKT)

Hong Kong $(\mathrm{CNN})$ - A local court in the far western Chinese province of Xinjiang has sentenced to death a Uyghur man who it says led an attack in a busy street last month that left 15 people dead, Chinese state media reported.

The World Uyghur Congress, an exile group, condemned the sentence and contested the Chinese authorities' account of the violence. It also questioned whether the defendant, Abdukerem Mamut, received a fair trial.

The court in the Xinjiang Uyghur Autonomous Region convicted Mamut of "organizing and heading a terrorist group, and intentional killing" and sentenced him to death on Monday, the Global Times, an English-language newspaper run by the Communist Party, reported.

It said Mamut and other members of the group killed 15 people and wounded 14 others "with axes and knives" in Yecheng County on February 28. The police detained Mamut at the scene and shot dead the other attackers, according to the report.

The Chinese authorities said four policemen were wounded and one local security officer was killed in the clash.

But the World Uyghur Congress offered a different version of events, saying that according to unidentified local people, the violence left 10 Uyghurs, seven members of the security forces and five other people dead, as well as 11 Uyghurs wounded.

The Chinese authorities have often blamed militants of Uyghur descent for outbreaks of violence in Xinjiang in recent years, labeling them terrorists.

Uyghurs are ethnic Turks who are linguistically, culturally and religiously distinct from China's majority Han population.

The quick conviction and sentencing of Mamut in connection with the violence "casts serious doubts on the legitimacy of the trial, and we do not believe that it met international legal standards," Rebiya Kadeer, the president of the congress, said in a statement published Tuesday on the organization's website.

"The death sentence is not only used arbitrarily against Uyghurs who dare to stand up for their basic human rights, but also to intimidate the Uyghur population," Kadeer said.

Xinjiang was rocked by the worst violence in decades in July 2009 when rioting between Uyghurs and Han Chinese left nearly 200 people dead and 1,700 wounded in the regional capital, Urumqi.

Last year, the authorities carried out a two-month security operation, which ended in October, against violence, terrorism and radical Islam across Xinjiang, a resource-rich region, which borders Pakistan, Afghanistan and several Central Asian states.

The tightened security measures included 24-hour security patrols of troubled areas, identity checks and random street searches of people and vehicles. 
The crackdowns on Uyghurs in the region have continued, the Uyghur congress said Tuesday, reporting a rise in arbitrary detentions and noting a string of clashes between the authorities and the local population. The Chinese authorities in Xinjiang said in January that they planned to recruit 8,000 extra police officers.

Uyghur activists say the crackdowns heighten anger among local Uyghurs who already accuse the government of religious and political repression.

Uyghurs also say they feel economically disadvantaged as a thriving Han population continues to move into the region.

CNN's Jethro Mullen and Judy Kwon contributed to this report.

http://edition.cnn.com/2012/03/28/world/asia/china-xinjiang-death-sentence/?hpt=wo_c2

Appendix B-Transitivity Analysis

(All processes are underlined, participants are marked though [], circumstances $<>$ )

(Sentences marked with a. come from China Daily while sentences marked with b. from CNN)

1. a. [Xinjiang terrorist] gets [death sentence].

1. b. [China] sentences [Uyghur man] to death $<$ after violence $>$.

2. a. [The ringleader of a terrorist group] was sentenced to death $<$ on Monday $><$ by the Intermediate People's Court of Kashgar prefecture in the Xinjiang Uygur autonomous region>.

2. b. [A local court in the far western Chinese province of Xinjiang] has sentenced to death [a Uyghur man who it says led an attack in a busy street last month that left 15 people dead], [Chinese state media] reported.

3. a. [Abdukerim Mamut] was found guilty of running a terrorist organization, leading terrorist attacks and murder, <according to Tianshannet, a news website run by the regional government's information office.>

3. b. [The court in the Xinjiang Uyghur Autonomous Region] convicted [Mamut] of "organizing and heading a terrorist group, and intentional killing" and sentenced [him] to death <on Monday>, [the Global Times, an English-language newspaper run by the Communist Party], reported.

4. a. $<$ At $6 \mathrm{pm}>$, [they] went $<$ to a crowded pedestrian street - Xingfu Road in Yecheng county near Kashgar in the southern Xinjiang $>-$ and attacked [people] $<$ with the knives and axes $>$. [Thirteen people] died and [16] were injured. [Two of those people] $<$ later $>$ died.

[Police] rushed $<$ to the scene $>$ and [Mamut] was captured. [They] shot [seven terrorists] dead and [one] was wounded and $<$ later $>$ died.

4. b. [It] said [Mamut and other members of the group killed 15 people and wounded 14 others "with axes and knives" in Yecheng County on February 28]. [The police] detained [Mamut] $<$ at the scene $>$ and shot dead [the other attackers], <according to the report>.

5. a. [One member from the public order joint defense force] was killed and [four police officers] were injured.

5. b. [The Chinese authorities] said [four policemen were wounded and one local security officer was killed in the clash].

6. a. [Zhang Chunxian, the Party chief of the region], <recently $>$ said [the attack was the result of agitation by overseas separatists, extremists and terrorists].

6. b. [The Chinese authorities] have often blamed [militants of Uyghur descent] $<$ for outbreaks of violence in Xinjiang in recent years, labeling them terrorists $>$.

7. a. [Two similar terrorist attacks] occurred $<$ in the prefecture in July, killing 14 people and leaving 42 wounded>.

7. b. [Xinjiang] was rocked $<$ by the worst violence in decades in July 2009 when rioting between Uyghurs and Han Chinese left nearly 200 people dead and 1,700 wounded in the regional capital, Urumqi $>$.

\section{Copyrights}

Copyright for this article is retained by the author(s), with first publication rights granted to the journal.

This is an open-access article distributed under the terms and conditions of the Creative Commons Attribution license (http://creativecommons.org/licenses/by/3.0/). 